European Journal of Personality

Eur. J. Pers. 14: 1-19 (2000)

\title{
Predicting Observers' Ratings of the Big Five from the CPI, HPI, and NEO- PI-R: A Comparative Validity Study ${ }^{1}$
}

\author{
JOHN A. JOHNSON* \\ Pennsy/vania State University, DuBois, PA, USA
}

\begin{abstract}
The present study compares the ability of three widely used personality inventories to predict averaged acquaintance ratings. Scores from 135 individuals on the California Psychological Inventory (CPI; Gough, 1987), Hogan Personality Inventory (HPI; Hogan and Hogan, 1992) and NEO Personality Inventory (NEO-PI-R; Costa and $M c C r a e, 1992)$ were correlated with four sets of acquaintance ratings representing four variants of the Five-Factor Model. Validity coefficients for the NEO-PI-R primary domain scales equalled or surpassed the CPI and HPI validity coefficients. Across all inventory scales and subscales, the magnitude of validity coefficients was moderated by the congruence between a predictor's and criterion's secondary factor loading. Copyright (C) 2000 John Wiley \& Sons, Ltd.
\end{abstract}

\section{INTRODUCTION}

Self-report personality inventories have many uses, but one of the primary purposes of self-reports is to 'classify people in the way that others classify them' (Gough, 1987, p. 3). For example, according to Gough (1987) '... a scale for dominance [should] in fact identify people who are described as dominant ...' and '... a scale for responsibility [should] accurately classif[y] people who are consensually described as responsible ...' (p. 3). This view is shared by Hogan and Hogan (1992), who suggest that a self-report inventory is useful to the degree that it faithfully represents one's public reputation, i.e. how a person is regarded by others. Similarly, Hofstee (1994) argues, 'The averaged judgment of knowledgeable others provides the best available point of

\footnotetext{
*Correspondence to: John A. Johnson, Department of Psychology, Pennsylvania State University DuBois, College Place, DuBois, PA 15801, USA; e-mail address: j5j@psu.edu

${ }^{1}$ This article is based on an invited paper made available at the symposium on Facets of Personality at the 8th Conference of the European Association of Personality Psychology, Ghent, 1996. The author was unable to be there in person to deliver it.
}

CCC 0890-2070/2000/010001-19\$17.50

Copyright (C) 2000 John Wiley \& Sons, Ltd. 
reference for ... assessing someone's personality' (p. 149) and therefore represents an important criterion against which self-reports should be validated. According to Goldberg (1999), comparative validity studies of different instruments as predictors of the same criteria are lacking and badly needed. The purpose of the study described in this paper is to compare how well three widely used self-report inventories predict this important criterion, averaged perceptions of others.

\section{The Big Five Domains of Observer Perceptions of Personality}

Over 50 years, factor analyses on acquaintance ratings, from Thurstone (1934) to Goldberg $(1990,1992)$, have demonstrated repeatedly that acquaintance perceptions cover five broad domains, dubbed the 'Big Five' by Lewis Goldberg $(1981,1993)$. As would be expected if self-reports isomorphically represent acquaintance perceptions, self-report inventories with sufficient length and diverse content also tap the same five domains (Costa, Busch, Zonderman and McCrae, 1986; Costa and McCrae, 1988; McCrae and Costa, 1985a, 1987, 1989a, 1989b; McCrae, Costa and Piedmont, 1993). The pervasive recurrence of the Big Five suggests they be used to organize a study comparing personality inventories' abilities to predict acquaintance ratings.

\section{AB5C Facets of the Big Five}

One hurdle that must be cleared before using the Big Five as a framework for a comparative rating study is the fact that different researchers conceptualize the five domains in somewhat different ways (Digman, 1990; John, 1990). Domain I has been conceptualized as extraversion, agency, or surgency, domain II as agreeableness or likeability or love, domain III as conscientiousness, prudence, constraint, or will to achieve, domain IV as emotional stability, adjustment, or (at the low end) neuroticism, and domain $\mathrm{V}$ as imagination, intellect, openness to experience, or creativity. Whenever possible, this article attempts to refer to the five domains by number only. Particular labels, when used, do not necessarily reflect complete endorsement of the conceptualization of the domain by the researcher who suggested the label.

Johnson and Ostendorf (1993) explained differences among the various conceptualizations of the Big Five as follows. They noted that the basic elements entered into a factor analysis (whether the elements are trait-words, bipolar rating scales, inventory items, or subscale or full-scale scores) typically are not pure markers of the derived factors. Most often, the factored elements contain a primary and secondary psychological meaning, represented by the highest and second highest loadings in the factor matrix (Hofstee, De Raad and Goldberg, 1992). Disagreements about domains arise from the often-overlooked secondary aspects of researchers' elements.

To wit, Hofstee et al. (1992) note that different collections of trait terms designed to assess the same domain conceivably could measure somewhat different constructs if the secondary aspects of the traits differ systematically. For example, if one used ratings of alert, ambitious, firm, and purposeful (all with primary loadings on the third 
factor and secondary loadings on the first factor, or $3+1+)$ to measure conscientiousness (domain III), one would actually be measuring an extroverted (1+) form of conscientiousness. The overall character of the scale would be $3+1+$. On the other hand, using ratings of careful, cautious, punctual, and formal (all $3+1-$ ) would assess an introverted (1-) form of conscientiousness. This scale would have a $3+1-$ character. Researchers using $3+1+$ scales would probably view domain III as Will to Achieve (Digman and Takemoto-Chock, 1981), whereas researchers using $3+1-$ scales would be more likely to view the domain as Constraint (Tellegen and Waller, 1999).

Hofstee et al. (1992) provide a geometric representation of a trait's primary and secondary loadings in Big Five factor space with what they call the Abridged Big Five Circumplex (AB5C) model. The AB5C mode consists of ten circumplexes defined by all possible pairing of the Big Five domains $(\mathrm{I} \times \mathrm{II}, \mathrm{I} \times \mathrm{III}, \ldots, \mathrm{IV} \times \mathrm{V})$. Each circumplex is sectioned, like slices of a pie, into $1230^{\circ}$ facets. Computational details for assigning traits to facets within the AB5C model are presented in the Analyses section below, but, in general terms, traits are assigned to the circumplex whose $x$-and $y$-axes represent the two Big Five domains on which the trait shows its primary and secondary loadings.

Johnson and Ostendorf (1993) documented differences in the secondary aspect of the AB5C depictions of Big Five rating scales used by followers of four different research programs: Hogan and Johnson (1981), McCrae and Costa (1985b, 1987), Norman (1963), and Goldberg (1992). For example, they found that domain V seemed to be operationalized as constrained intellect $(5+3+)$ by Goldberg's (1992) rating scale and as surgent intellect $(5+1+)$ by the Openness to Experience rating scale of McCrae and Costa (1985b, 1987) (see also Johnson, 1994a).

The main hypothesis of the present study is that when self-report and acquaintance-rating scales share the same primary and secondary aspects, self-observer correlations will be higher than when the scales share only the same primary aspect, and that still lower correlations will be found when the scales' primary aspect is the same but the secondary aspect is opposite in sign. For example, correlations between self-reports and acquaintance ratings are predicted to be highest if both are measured with $5+3+$ scales, slightly lower if one scale is $5+3+$ and the other is $5+1+$, and lower still if one scale is $5+3+$ and the other is $5+3-$. Presumably, the theoretical predilections of scale authors (Johnson, Germer, Efran, and Overton, 1988) lead to selectivity in item choice, such that inventories and rating scales authored by the same researcher will often share the same AB5C character. Should this happen, the researcher's self-report scale for a particular domain would predict that researcher's ratings scales better than the self-report scale of another researcher who conceptualizes the domain slightly differently.

For example, if the conceptualization of domain V, Openness to Experience, of Costa and McCrae represents an extroverted or surgent form of that domain $(5+1+)$, both their self-report Openness to Experience scale (Costa and McCrae, 1992) and the adjectives they assembled for acquaintance ratings of the domain (McCrae and Costa, 1985b, 1987) would be expected to possess this $5+1+$ character. Consequently, Openness to Experience would be expected to predict McCrae and Costa's acquaintance ratings of domain $\mathrm{V}$ better than a self-report scale such as the Intellectance scale of Hogan and Hogan (1992), which has a $5+3-$ character (Johnson, 1994a). 
METHOD

\section{Participants}

Data were collected from 148 undergraduate students (45 male, 98 female, five sex unknown) who volunteered to participate in a doctoral dissertation project by Cawley (1998). Fully completed questionnaires were received from 135 participants (40 male, 95 female); only these data were analyzed. Volunteers received extra credit points for the courses in which they were enrolled.

\section{Personality Scales}

Participants completed three widely used personality inventories: the NEO-PI-R (Costa and McCrae, 1992), the Hogan Personality Inventory (HPI; Hogan and Hogan, 1992), and the California Psychological Inventory (CPI; Gough, 1987).

The primary NEO-PI-R scales Extraversion, Agreeableness, Conscientiousness, Neuroticism, and Openness to Experience represent Big Five domains I through V. Each primary scale is comprised of six subscales termed facets by Costa and McCrae. Johnson (1994a) suggests how the NEO-PI-R scales and facet subscales might be assigned to AB5C facets.

The primary HPI scales Sociability and Ambition represent Big Five domain I; Likeability, domain II; Prudence, domain III; Adjustment, domain IV; and Intellectance and School Success, domain V. Each HPI primary scale is comprised of four to eight homogeneous item composite subscales, or HICs. Johnson (1994a) suggests how the HPI scales and HICs might be assigned to AB5C facets.

Unlike the development of NEO-PI-R and HPI, the construction of the CPI was not informed by the Big Five. Nonetheless, the author of the CPI, Harrison Gough (personal communication, 12 September 1995), has suggested that Big Five domains I through V are adequately represented by CPI scales Sociability, Amicability, Socialization, Well-Being, and Creative Temperament. Recent empirical findings (Johnson, 1997) support Gough's suggestion. These five scales do not contain subscales and have not been subjected to AB5C analyses until now.

\section{Rating Criteria}

Participants were instructed to have two acquaintances who knew them well to rate them with the four sets of Big Five scales used by Johnson and Ostendorf (1993). The four sets of bipolar rating scales represent four versions of the Five Factor Model (FFM). The Hogan-Johnson (1981) measure contains 49 Likert scales anchored by bipolar adjectives and represents Hogan's $(1983,1996)$ socioanalytic view of the FFM. McCrae and Costa (1985b, 1987) developed a set of 80 Likert rating scales to parallel the domains measured by their NEO-PI-R. Norman's (1963) peer rating study was summarized by a table of 20 bipolar terms, and these terms have subsequently been used by numerous researchers to anchor Likert rating scales. Goldberg (1992) developed a number of alternative marker scales for the Big Five; the present study uses his 50 Likert scales anchored by bipolar adjectives. Further details on the nature of the rating scales can be found in the articles by Johnson and Ostendorf (1993), Hogan and Johnson (1981), Hogan (1983, 1996), McCrae and Costa (1985b, 1987), Norman (1963), and Goldberg (1992). Raters were given a choice of either 
mailing their ratings directly to the investigator or sealing their ratings in an envelope to be returned via the participants. Characteristics of raters were not assessed in this study, but in previous, similar studies (Johnson and Ostendorf, 1993) about half of the participants chose close friends and about half chose family members to rate them.

\section{Analyses}

Ascertaining the location of personality scales with the AB5C model

The first set of analyses determined the location of all personality scales used in this project within the AB5C model. Although suggested AB5C depictions for the rating scales were provided by Johnson and Ostendorf (1993) and AB5C depictions of the NEO-PI-R facets and HPI HICs were provided by Johnson (1994a), three considerations suggested calculating AB5C depictions for the scales anew.

First, factor loadings can vary from sample to sample, and it makes sense to interpret findings in the present study in terms of factor loadings found within the study. This consideration is particularly important for determining the $\mathrm{AB} 5 \mathrm{C}$ character of the NEO-PI-R and HPI scales because Johnson (1994a) derived AB5C assignments from factor analyses from the limited number of each inventory's own subscales rather than a factor analysis of a more extensive set of trait adjectives. Second, AB5C assignments for each full scale previously suggested by Johnson and Ostendorf (1993) and Johnson (1994a) are rough approximations based on the preponderance of $\mathrm{AB} 5 \mathrm{C}$ locations of the scales' component subscales. These rough approximations do not always provide a definitive overall $\mathrm{AB} 5 \mathrm{C}$ assignment; for example, the Openness to Experience scale of Costa and McCrae (1992) consists of two $5+1+$ facets, two $5+3-$ facets, and two $5+5+$ facets. Finally, to date no AB5C assignments had been computed for CPI scales.

To compute $\mathrm{AB} 5 \mathrm{C}$ locations for all rating and inventory scales, I used a method nearly identical to the one employed by Hofstee, De Raad and Goldberg (1992). First, I scored each of the 199 individual Likert scales from the four rating instruments used by Johnson and Ostendorf (1993). These 199 bipolar scales included 50 scales from Goldberg (1992), 49 from Hogan and Johnson (1981), 80 from McCrae and Costa (1985b), and 20 from Norman (1963). These 199 scores were subjected to a principal components factor analysis with varimax rotation. ${ }^{2}$ Factor scores were computed from a five-factor solution.

Next, scale scores from all four rating instruments and from the CPI, HPI, and NEO-PI-R (including subscales of the HPI and NEO-PI-R) were correlated with the factor scores from the principal components analysis, producing a matrix of factor loadings. The exact relationship between scores on a particular personality scale and any pair of factor scores is represented by the multiple correlation of that personality scale with the two orthogonal factors:

$$
R=\sqrt{l_{1}^{2}+l_{2}^{2}}
$$

\footnotetext{
${ }^{2}$ Using more variables than observations violates a canon of factor analysis. This violation could have been avoided by treating different acquaintance ratings of the same participant as different observations instead of averaging them. Breaking the rules of factor analysis did not seem to make a difference here. Results highly similar to those presented here were found by factoring adjective scale scores rather than individual adjective ratings.
} 
where $l_{1}$ and $l_{2}$ represent the scale's loadings on the two factors. Geometrically, $l_{1}$ and $l_{2}$ represent the coordinates of the scale in a two-dimensional space defined by the two factors, and the multiple correlation, $R$, is the length of the vector from the origin (Wiggins and Broughton, 1991). Alternatively, the multiple correlation between a scale and two orthogonal factors can be calculated as follows:

$$
R=\left|l_{1} \cos \left(a_{1}\right)\right|+\left|l_{2} \cos \left(a_{2}\right)\right|
$$

where $l_{1}$ represents the larger of the two factor loadings and $l_{2}$ the smaller loading; $a_{1}$ represents the angle between the $R$ vector and the axis underlying the larger loading, and $a_{2}$ is $\left(90^{\circ}-a_{1}\right)$.

Rather than retaining a personality scale's exact angular location, the $\mathrm{AB} 5 \mathrm{C}$ model projects the scale onto the closest factor vector located at a multiple of $30^{\circ}(0,30,60$, $\left.\ldots, 330^{\circ}\right)$. The projection on this vector, $p$, can be found by the equation

$$
p=\left|l_{1}\right| \cos \left(30^{\circ}\right)+\left|l_{2}\right| \cos \left(60^{\circ}\right)
$$

where $l_{1}$ and $l_{2}$ are the absolute values of the primary and secondary loadings, respectively (Hofstee et al., 1992). Because the $p$ vector is very close to the $R$ vector (within $15^{\circ}$ ), $p$ will be within 0.05 of the actual $R$.

I used the FORTRAN program written by Fritz Ostendorf (Johnson and Ostendorf, 1993; available from the author) to compute projections for each personality scale on the 90 factor vectors. (In addition to the ten vectors representing the positive and negative poles of the five orthogonal factors, in each of the ten circumplexes there are eight vectors inserted at the $30,60,120,150,210,240,300$, and $330^{\circ}$ locations.) By identifying the highest projection, the program assigns scales to $\mathrm{AB} 5 \mathrm{C}$ facets defined by each scale's highest (primary) and second-highest (secondary) factor loadings. For example, the CPI Sociability scale's two highest loadings were 0.34 on Factor I and 0.14 on Factor IV; consequently it was assigned to the $1+4+$ facet. If a scale's primary loading were at least 3.73 (i.e. contingent of $15^{\circ}$ ) as large as the secondary loading, the nearest factor vector would lie at $0,90,180$, or $270^{\circ}$. In these cases the scale would be assigned to the AB5C facet associated with the primary loading (see Hofstee et al., 1992). For example, the two highest loadings of the Sociality scale of Hogan and Johnson (1981) were 0.86 on Factor I and 0.19 on Factor II; consequently it was assigned to the $1+1+\mathrm{AB} 5 \mathrm{C}$ facet.

\section{Comparing predictive validity of the CPI, HPI, and NEO-PI-R}

The second set of analyses involved assessing the relative abilities of the CPI, HPI, and NEO-PI-R to predict the acquaintance ratings. This was accomplished by correlating scores from the three self-report inventories with the four sets of rating scales. The correlation matrix was visually inspected to see whether correlations tended to be higher for self-report scales and acquaintance rating scales that shared a common $\mathrm{AB} 5 \mathrm{C}$ depiction. The small number of $\mathrm{AB} 5 \mathrm{C}$ configurations emerging from these analyses limited the opportunities to test, statistically, whether scales sharing the same primary and secondary loading correlated higher than scales sharing only the same primary loading. The last set of analyses was designed to overcome this limitation. 
Predicting scales built from items located within the same AB5C facet

The third and final set of analyses was designed to overcome the limited range of AB5C configurations covered by the standard inventory and rating scales. The standard scales on the three inventories cover only 14 of the 45 bipolar facets (e.g. $1+2-$ versus $1-2+$ ) in the AB5C model. The standard rating scales cover 16 of the 45 facets. The final set of analyses investigated how well new rating scales comprised of items selected from the same AB5C facet were predicted by the full-scale and subscale scores of the self-report inventories.

The new scales were formed by assembling items that fell in the same AB5C facet with the stipulation that there must be at least three such items. These AB5C scales were correlated with both full-scale scores from all three personality inventories and subscale scores from the NEO-PI-R and HPI. Correlations involving full scales, NEO-PI-R facet-subscales, and HPI HIC-subscales were analyzed separately. Correlations were sorted into one of three categories. Category 1 contained correlations based on self-report scales and acquaintance rating scales that fell into the same or adjacent $\mathrm{AB} 5 \mathrm{C}$ facets. Most of these cases involved scales with exactly the same primary and secondary loadings (e.g. both $5+3+$ ), but for a few cases the primary and secondary loadings were reversed (e.g. one scale was $5+3+$ and the other $3+5+)$. Category 2 contained correlations between scales with the same primary loading but different secondary loadings (e.g. $5+3+$ and $5+1+$ ). Category 3 contained correlations between scales that shared the same primary loading but differed in sign of the secondary loading (e.g. $5+3+$ and $5+3-$ ).

Correlations were converted by Fisher's $r$ to $z$ transformation (McNemar, 1969), averaged within each category, and then converted back to $r$. It was predicted that the mean category $1 r$ would be larger than the mean category $2 r$, which, in turn, would be larger than the mean category $3 r$. This prediction was tested separately for the selfreport inventory full-scales, the NEO-PI-R facet subscales, and the HPI HIC subscales. Contrast weights of 1,0 , and -1 for categories 1,2 , and 3 correlations were used in equation (6) from Meng, Rosenthal, and Rubin (1992).

\section{RESULTS}

\section{AB5C Character of Personality Scales}

A scree plot from the principal components analysis of the acquaintance ratings clearly suggested a five-factor solution. The correlations between all personality scales and the five-factor scores from the factor analysis are presented in Table 1. Table 1 also shows the assignment of all personality scales to AB5C facets and the projections on these facets.

Table 1 also compares scales' AB5C assignments calculated in this study to AB5C depictions suggested in previous studies (Johnson, 1994a; Johnson and Ostendorf, 1993). For the primary scales analyzed previously, 17 showed AB5C locations identical to those calculated in this study, two showed the primary and secondary aspects reversed, and 15 showed differences in the secondary aspect. AB5C locations of the NEO-PI-R facet and HPI HIC subscales were even less stable. This less-than-perfect stability of secondary loadings across samples confirms the need to derive AB5C locations on local data. 


\begin{tabular}{|c|c|c|c|c|c|c|c|c|}
\hline \multirow[t]{2}{*}{ Scale } & \multicolumn{5}{|c|}{ Factor Scores } & \multicolumn{3}{|c|}{ AB5C Facets } \\
\hline & I & II & III & IV & $\mathrm{V}$ & Projection & Present & Previous \\
\hline \multicolumn{9}{|l|}{ Gough's CPI } \\
\hline Sociability & 0.34 & -0.06 & -0.03 & 0.14 & 0.05 & 0.364 & $1+4+$ & - \\
\hline Amicability & -0.03 & 0.29 & 0.22 & 0.09 & -0.08 & 0.363 & $2+3+$ & - \\
\hline Socialization & -0.09 & 0.21 & 0.34 & 0.19 & -0.18 & 0.403 & $3+2+$ & - \\
\hline Well-Being & 0.10 & 0.14 & 0.21 & 0.22 & 0.02 & 0.294 & $4+3+$ & - \\
\hline Creative Temperament & 0.21 & 0.05 & -0.28 & -0.01 & 0.26 & 0.374 & $3-5+$ & - \\
\hline \multicolumn{9}{|l|}{ Hogan \& Hogan's HPI } \\
\hline Sociability & 0.35 & -0.06 & -0.13 & 0.12 & 0.01 & 0.366 & $1+3-$ & $1+3-$ \\
\hline SO1 Likes Parties & 0.30 & 0.01 & -0.04 & 0.04 & -0.15 & 0.337 & $1+5-$ & $1+1+$ \\
\hline SO2 Likes Crowds & 0.21 & -0.08 & 0.07 & 0.16 & -0.13 & 0.262 & $1+4+$ & $1+1+$ \\
\hline SO3 Experience-Seeking & 0.19 & -0.06 & -0.06 & 0.05 & 0.25 & 0.308 & $5+1+$ & $3-1+$ \\
\hline SO4 Exhibitionistic & 0.21 & -0.07 & -0.14 & 0.07 & 0.03 & 0.248 & $1+3-$ & $1+3-$ \\
\hline SO5 Entertaining & 0.27 & 0.00 & -0.30 & 0.08 & 0.02 & 0.396 & $3-1+$ & $1+3-$ \\
\hline Ambition & 0.26 & -0.17 & 0.15 & 0.22 & 0.04 & 0.340 & $1+4+$ & $4+1+$ \\
\hline AM1 Competitive & 0.22 & -0.14 & 0.33 & 0.07 & 0.06 & 0.400 & $3+1+$ & $1+5+$ \\
\hline AM2 Self-Confidence & 0.07 & -0.16 & -0.08 & 0.22 & 0.07 & 0.275 & $4+2-$ & $1+4+$ \\
\hline AM3 No Depression & 0.02 & 0.13 & 0.15 & 0.21 & -0.01 & 0.257 & $4+3+$ & $2+4+$ \\
\hline AM4 Leadership & 0.24 & -0.33 & 0.05 & 0.16 & -0.01 & 0.408 & $2-1+$ & $5+3-$ \\
\hline AM5 Identity & -0.03 & -0.03 & 0.15 & 0.02 & -0.08 & 0.175 & $3+5-$ & $4+4+$ \\
\hline AM6 No Social Anxiety & 0.32 & -0.03 & -0.04 & 0.13 & 0.13 & 0.339 & $1+5+$ & $4+1+$ \\
\hline Likeability & 0.22 & 0.35 & 0.20 & -0.12 & -0.09 & 0.415 & $2+1+$ & $2+1+$ \\
\hline LI1 Easy-to-live-with & -0.06 & 0.32 & 0.19 & -0.01 & -0.14 & 0.372 & $2+3+$ & $2+1+$ \\
\hline LI2 Sensitive & 0.04 & 0.38 & 0.15 & -0.28 & -0.10 & 0.468 & $2+4-$ & $2+5+$ \\
\hline LI3 Caring & 0.12 & 0.31 & 0.12 & -0.13 & 0.00 & 0.328 & $2+4-$ & $2+1+$ \\
\hline LI4 Likes People & 0.37 & 0.11 & 0.09 & -0.07 & -0.10 & 0.374 & $1+2+$ & $1+2+$ \\
\hline LI5 No Hostility & 0.10 & 0.31 & 0.14 & -0.02 & -0.02 & 0.343 & $2+3+$ & $2+4+$ \\
\hline Prudence & -0.04 & 0.14 & 0.31 & -0.11 & -0.10 & 0.337 & $3+2+$ & $3+2+/ 1-$ \\
\hline PR1 Moralistic & 0.09 & -0.03 & 0.03 & 0.14 & 0.07 & 0.162 & $4+1+$ & $4+2+$ \\
\hline PR2 Mastery & 0.06 & 0.03 & 0.34 & -0.01 & -0.09 & 0.336 & $3+3+$ & $5+3+$ \\
\hline PR3 Virtuous & 0.11 & 0.39 & 0.19 & 0.01 & 0.06 & 0.430 & $2+3+$ & $2+1-$ \\
\hline
\end{tabular}




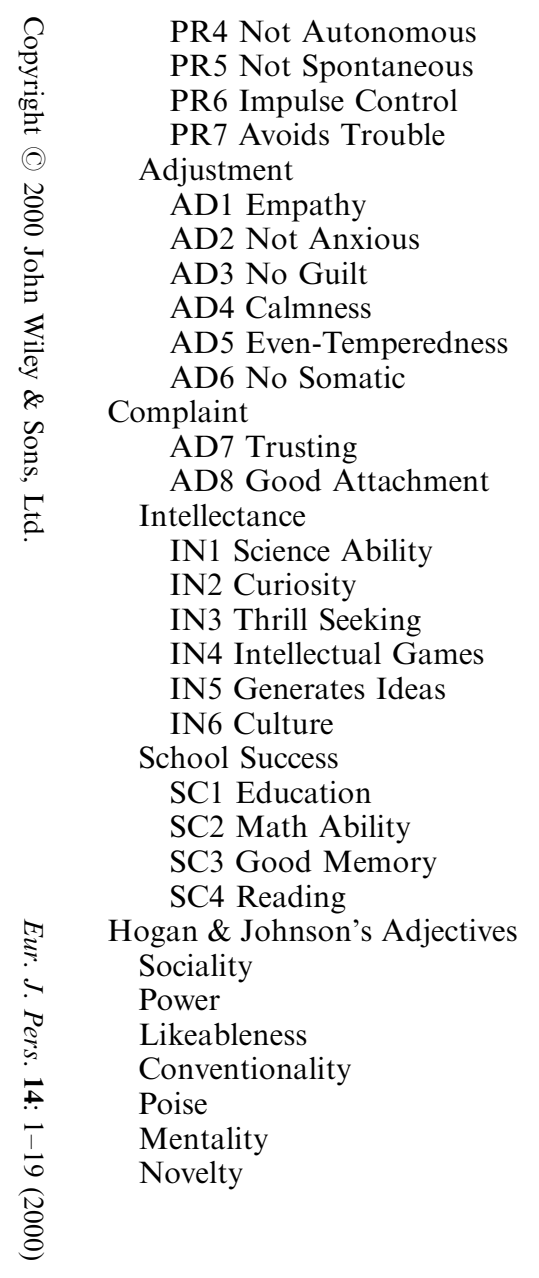

\begin{tabular}{|c|c|c|c|c|c|c|c|}
\hline-0.06 & 0.19 & 0.06 & -0.14 & -0.09 & 0.236 & $2+4-$ & $3+2+$ \\
\hline-0.09 & -0.06 & 0.22 & -0.20 & -0.02 & 0.297 & $3+4-$ & $1-3+$ \\
\hline-0.15 & -0.00 & 0.17 & -0.18 & -0.07 & 0.243 & $4-3+$ & $1-3+$ \\
\hline-0.03 & -0.01 & 0.04 & 0.08 & -0.21 & 0.227 & $5-4+$ & $3+2+$ \\
\hline 0.03 & 0.14 & 0.12 & 0.37 & -0.04 & 0.386 & $4+2+$ & $4+2+$ \\
\hline 0.13 & 0.34 & 0.19 & -0.27 & -0.04 & 0.432 & $2+4-$ & $2+4+$ \\
\hline 0.14 & -0.02 & -0.02 & 0.33 & 0.12 & 0.355 & $4+1+$ & $4+2+$ \\
\hline-0.07 & -0.01 & 0.12 & 0.19 & -0.01 & 0.220 & $4+3+$ & $4+2+$ \\
\hline 0.02 & -0.00 & 0.08 & 0.31 & 0.09 & 0.317 & $4+5+$ & $4+2+$ \\
\hline 0.02 & 0.26 & 0.08 & 0.17 & 0.04 & 0.308 & $2+4+$ & $4+2+$ \\
\hline 0.05 & 0.11 & 0.22 & 0.31 & -0.07 & 0.373 & $4+3+$ & $2+4+$ \\
\hline 0.13 & 0.26 & 0.34 & 0.06 & -0.03 & 0.428 & $3+2+$ & $2+4+$ \\
\hline-0.07 & -0.11 & 0.15 & 0.17 & -0.21 & 0.264 & $5-4+$ & $4+3+$ \\
\hline 0.17 & -0.01 & -0.23 & 0.10 & 0.40 & 0.461 & $5+3-$ & $5+3-$ \\
\hline 0.04 & 0.09 & -0.15 & 0.09 & 0.23 & 0.270 & $5+3-$ & $5+3-$ \\
\hline-0.08 & -0.10 & 0.01 & -0.03 & 0.01 & 0.126 & $2-1-$ & $3-3-$ \\
\hline 0.12 & -0.05 & -0.06 & 0.09 & 0.07 & 0.149 & $1+4+$ & $3-1+$ \\
\hline-0.11 & -0.02 & -0.09 & 0.09 & 0.09 & 0.137 & $1-5+$ & $5+2+$ \\
\hline 0.38 & -0.08 & -0.17 & 0.11 & 0.26 & 0.456 & $1+5+$ & $5+3-$ \\
\hline-0.00 & 0.11 & -0.19 & -0.10 & 0.46 & 0.493 & $5+3-$ & $3-5+$ \\
\hline-0.06 & -0.14 & -0.08 & 0.11 & 0.30 & 0.328 & $5+2-$ & $5+5+$ \\
\hline-0.16 & -0.03 & -0.01 & 0.05 & 0.18 & 0.240 & $5+1-$ & $5+1+$ \\
\hline 0.01 & -0.07 & 0.00 & 0.06 & 0.10 & 0.120 & $5+2-$ & $5+4+$ \\
\hline-0.08 & -0.15 & -0.00 & 0.14 & 0.15 & 0.207 & $5+2-$ & $5+5+$ \\
\hline 0.06 & -0.10 & -0.16 & 0.03 & 0.30 & 0.341 & $5+3-$ & $5+5+$ \\
\hline 0.86 & 0.19 & -0.07 & 0.04 & 0.10 & 0.856 & $1+1+$ & $1+1+$ \\
\hline 0.66 & -0.17 & 0.45 & -0.08 & 0.32 & 0.794 & $1+3+$ & $1+3+$ \\
\hline-0.08 & 0.84 & 0.13 & 0.16 & -0.01 & 0.844 & $2+2+$ & $2+4+$ \\
\hline 0.13 & 0.31 & 0.82 & 0.03 & 0.04 & 0.870 & $3+2+$ & $3+2+$ \\
\hline 0.26 & 0.23 & 0.20 & 0.81 & 0.08 & 0.835 & $4+1+$ & $4+1+$ \\
\hline 0.17 & -0.09 & 0.09 & 0.07 & 0.80 & 0.799 & $5+5+$ & $5+3+$ \\
\hline 0.44 & -0.08 & -0.30 & 0.06 & 0.44 & 0.597 & $1+5+$ & $5+1+$ \\
\hline
\end{tabular}


Table 1. Continued

\begin{tabular}{|c|c|c|c|c|c|c|c|c|}
\hline \multirow[t]{2}{*}{ Scale } & \multicolumn{5}{|c|}{ Factor Scores } & \multicolumn{3}{|c|}{ AB5C Facets } \\
\hline & I & II & III & IV & $\mathrm{V}$ & Projection & Present & Previous \\
\hline \multicolumn{9}{|l|}{ Costa \& McCrae's NEO-PI-R } \\
\hline Extraversion & 0.47 & 0.05 & 0.14 & 0.02 & -0.04 & 0.477 & $1+3+$ & $1+3+$ \\
\hline E1 Warmth & 0.31 & 0.41 & 0.16 & -0.08 & -0.11 & 0.513 & $2+1+$ & $1+2+$ \\
\hline E2 Gregariousness & 0.34 & 0.15 & 0.06 & 0.10 & -0.26 & 0.424 & $1+5-$ & $1+4+$ \\
\hline E3 Assertiveness & 0.37 & -0.30 & 0.11 & 0.15 & 0.12 & 0.470 & $1+2-$ & $1+3+$ \\
\hline E4 Activity & 0.29 & -0.14 & 0.17 & -0.02 & 0.15 & 0.334 & $1+3+$ & $1+3+$ \\
\hline E5 Excitement Seeking & 0.23 & -0.14 & 0.04 & -0.07 & 0.03 & 0.269 & $1+2-$ & $1+2-$ \\
\hline E6 Positive Emotions & 0.29 & 0.23 & 0.03 & -0.03 & -0.04 & 0.364 & $1+2+$ & $1+1+$ \\
\hline Agreeableness & -0.01 & 0.47 & 0.19 & -0.17 & -0.04 & 0.502 & $2+3+$ & $2+1+$ \\
\hline A1 Trust & 0.06 & 0.27 & 0.17 & -0.03 & -0.07 & 0.320 & $2+3+$ & $2+4+$ \\
\hline A2 Straightforwardness & -0.11 & 0.25 & 0.21 & -0.18 & -0.04 & 0.322 & $2+3+$ & $2+3+$ \\
\hline A3 Altruism & 0.11 & 0.43 & 0.26 & -0.12 & -0.11 & 0.504 & $2+3+$ & $2+1+$ \\
\hline A4 Compliance & -0.04 & 0.45 & 0.11 & -0.08 & -0.05 & 0.454 & $2+2+$ & $2+2+$ \\
\hline A5 Modesty & -0.07 & 0.26 & -0.05 & -0.19 & -0.01 & 0.320 & $2+4-$ & $2+4-$ \\
\hline A6 Tender-Mindedness & 0.02 & 0.26 & 0.05 & -0.06 & 0.21 & 0.335 & $2+5+$ & $2+1+$ \\
\hline Conscientiousness & -0.05 & -0.04 & 0.48 & 0.05 & 0.08 & 0.478 & $3+3+$ & $3+4+$ \\
\hline C1 Competence & 0.04 & -0.10 & 0.26 & 0.22 & 0.07 & 0.337 & $3+4+$ & $3+4+$ \\
\hline $\mathrm{C} 2$ Order & -0.03 & -0.11 & 0.39 & -0.11 & 0.03 & 0.397 & $3+2-$ & $3+5-$ \\
\hline C3 Dutifulness & -0.02 & 0.09 & 0.40 & 0.07 & 0.08 & 0.399 & $3+3+$ & $3+2+$ \\
\hline C4 Achievement Striving & 0.07 & -0.12 & 0.37 & -0.02 & 0.10 & 0.379 & $3+2-$ & $3+1+$ \\
\hline C5 Self-Discipline & 0.01 & -0.00 & 0.42 & 0.00 & 0.01 & 0.425 & $3+3+$ & $3+4+$ \\
\hline C6 Deliberation & -0.25 & 0.06 & 0.23 & 0.09 & 0.06 & 0.328 & $1-3+$ & $3+1-$ \\
\hline Neuroticism & -0.12 & -0.02 & -0.04 & -0.41 & -0.03 & 0.413 & $4-1-$ & $4-3-$ \\
\hline N1 Anxiety & -0.24 & 0.10 & 0.04 & -0.44 & -0.12 & 0.501 & $4-1-$ & $4-1-$ \\
\hline N2 Hostility & 0.01 & -0.36 & -0.05 & -0.22 & 0.03 & 0.424 & $2-4-$ & $4-2-$ \\
\hline N3 Depression & -0.07 & -0.03 & -0.02 & -0.31 & 0.01 & 0.313 & $4-4-$ & $4-3-$ \\
\hline N4 Self-Consciousness & -0.11 & 0.08 & 0.00 & -0.31 & -0.07 & 0.327 & $4-1-$ & $4-4-$ \\
\hline N5 Impulsiveness & 0.09 & 0.01 & -0.12 & -0.14 & 0.12 & 0.178 & $4-5+$ & $4-1+$ \\
\hline N6 Vulnerability & -0.17 & 0.18 & -0.07 & -0.38 & -0.11 & 0.418 & $4-2+$ & $4-3-$ \\
\hline
\end{tabular}




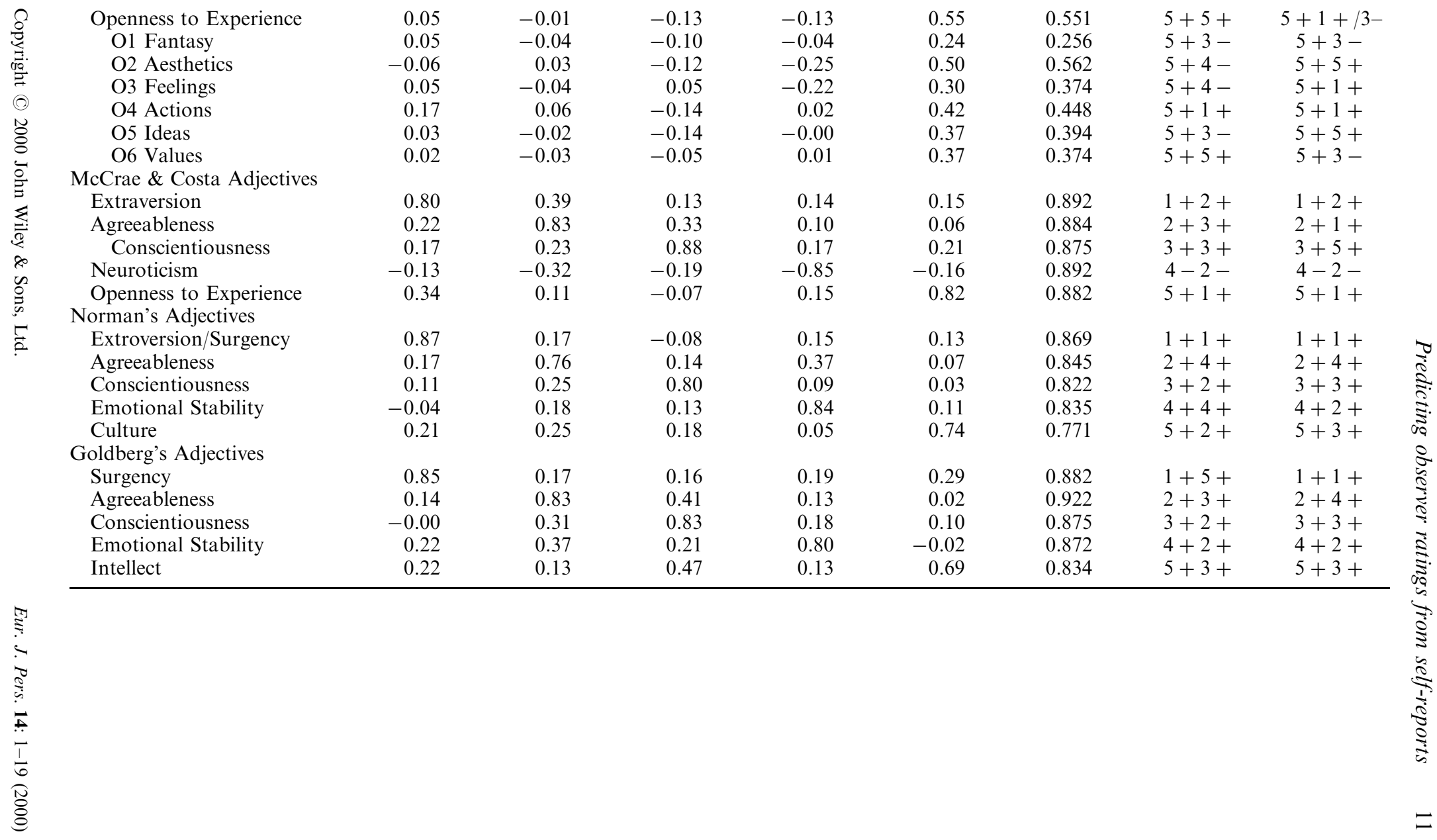




\section{Predictive Validity of CPI, HPI, and NEO-PI-R}

Table 2 presents a head-to-head comparison of the relative abilities of the CPI, HPI, and NEO-PI-R primary scales to predict acquaintance ratings of the Big Five domains. The small number of $\mathrm{AB} 5 \mathrm{C}$ facets represented by both self-report predictors and acquaintance rating criteria limited opportunities to directly test the main hypothesis, viz., that the highest correlations would be found for scales sharing the same primary and secondary loadings. The only area for such a test was domain IV, where the $4+2+$ HPI Adjustment scale and $4-1-$ NEO-PI-R Neuroticism scale were correlated with a $4+1+$ acquaintance rating scale and three different $4+2+$ acquaintance rating scales. Examination of these eight correlations indicated that the ability of a self-report scale to predict an acquaintance rating scale from the same domain did not depend upon predictor and criterion sharing an $\mathrm{AB} 5 \mathrm{C}$ secondary aspect. The HPI Adjustment and NEO-PI-R Neuroticism scales predicted the four criteria equally well.

The pattern that emerges in Table 2 appears to be a 'main effect' for the NEO-PI-R rather than a predictor-criterion interaction revolving around the secondary loadings of the scales. In 25 of the 27 possible comparisons of the three self-report inventories, the NEO-PI-R scales equalled or surpassed the abilities of the other self-report scales to predict the acquaintance ratings. In the other two cases, the NEO-PI-R based correlation was within $r=0.02$ of the strongest predictor. Overall, the average validity coefficient was for the NEO-PI-R primary scales $r=0.42$; for the CPI $r=0.28$, and for the HPI $r=0.30$. With contrast weights of $2,-1$, and -1 for these respective correlations, equation (6) of Meng et al. (1992) indicates a statistically significant difference between the average NEO-PI-R-based validity coefficient and the other two, $Z=2.01, p<0.05$ (two tailed).

\section{Prediction of Specially Constructed AB5C Scales}

Despite the consistent, if unexpected, superiority of the NEO-PI-R in predicting acquaintance ratings, too few $\mathrm{AB} 5 \mathrm{C}$ configurations in the predictors and criteria were present to test the importance of secondary loadings. To increase the variety of $\mathrm{AB} 5 \mathrm{C}$ configurations represented in the criteria, special 'AB5C scales' were constructed. AB5C facet assignments were examined for all 199 individual bipolar traits across the four rating inventories. Where three or more items possessed the same $\mathrm{AB} 5 \mathrm{C}$ assignment, they were grouped into scales. The specially constructed $\mathrm{AB} 5 \mathrm{C}$ rating scales covered 21 of the $45 \mathrm{AB} 5 \mathrm{C}$ facets; six of the new scales covered $\mathrm{AB} 5 \mathrm{C}$ facets not represented by the standard rating scales. The facets represented were (with the number of items in parentheses) as follows: domain I, $1+1+(4), 1+2+(10)$, $1+3+$ (7), $1+4+(5), 1+5+$ (8); domain II, $2+1+(5), 2+3+(18)$, $2+4+(17)$; domain III, $3+1+(7), 3+2+(19), 3+3+(5), 3+4+(5)$, $3+5+(8)$; domain IV, $4+1+(7), 4+2+(9), 4+4+(7)$; and domain V, $5+1+(11), 5+2+(3), 5+3+(11), 5+3-(4), 5+5+(3)$.

To increase the diversity of $\mathrm{AB} 5 \mathrm{C}$ configurations among the predictors, the NEOPI-R facet subscales and the HPI homogeneous item composite (HIC) subscales were assigned to $\mathrm{AB} 5 \mathrm{C}$ facets. This collection of subscales represented an additional 24 $\mathrm{AB} 5 \mathrm{C}$ facets beyond those marked by the standard, full scales. 
Table 3 compares the correlations based on (i) predictors and criteria with identical AB5C designations, (ii) predictors and criteria possessing the same primary loading but different secondary loadings, and (iii) predictors and criteria possessing the same primary loading and differing in sign on the secondary loading. As hypothesized, secondary loadings do make a difference. Self-report scales predicted acquaintancerating criteria best when predictor and criterion fell into the same $\mathrm{AB} 5 \mathrm{C}$ facet (e.g. both $5+3-$ ). Correlations were lower when predictor and criterion differed in their secondary loading (e.g. a $5+3-$ predictor and a $5+2+$ criterion) and were lower still when predictor and criterion differed in sign on their secondary loading (e.g. a $5+3-$ predictor and a $5+3+$ criterion). Results were statistically significant for the three separate sets of correlations tested (full scales for all inventories, NEO-PI-R facets, and HPI HICs).

\section{DISCUSSION}

The main hypothesis of this study - that self-report scales best predict acquaintancerating scales that share the same AB5C location - was confirmed. One might argue that this finding is trivial because it is mathematically necessary; a scale near the $5+3-$ vector must share more variance with another scale near that vector than with a scale located near the $5+2+$ vector. Nonetheless, without an empirical study of scales actually used in personality research, one cannot judge whether variance associated with the secondary loading is substantial enough to affect the interpretation of research findings. The current study suggests that secondary loadings are important, because the magnitude of validity coefficients for three widely used personality inventories depended on the secondary loadings of the inventory scales and rating criteria. Moreover, the differences in the validity coefficients were statistically significant. Hofstee et al. (1992, p. 147) speculate that 'neglect of secondary loadings may be responsible for at least some of the disputes and unclarities in the factor-analytic literature'. The current study supports and extends the proposition of Hofstee et al. Neglect of secondary loadings may cloud the interpretation of any correlational study, not just those employing factor analyses.

In addition to supporting the main hypothesis, the results of the current study turned up an unexpected finding: the NEO-PI-R scales appeared to predict acquaintance ratings better than the CPI and HPI scales. While this may cause rejoicing among NEO-PI-R advocates, NEO-PI-R users who discount the main findings of the present study do so only at their own peril. Ignoring the relative AB5C locations of the NEO-PI-R facet subscales and other assessments in a study may sometimes lead to great interpretive difficulties. For example, Trobst (1999) recently reported that personality changes after traumatic brain injury, as measured by the NEO-PI-R, for the most part confirm the changes noted in clinical lore, but one exception was impulsivity. Clinicians had reported increases in impulsivity following brain injury, but Trobst found no changes on the NEO-PI-R N5 Impulsiveness facet. This mystery dissolves, however, when one realizes that N5 Impulsiveness measures a neurotic type of impulsivity associated with giving in to cravings; this type of impulsivity fell into the $4-5+\mathrm{AB} 5 \mathrm{C}$ facet in the present study. According to Johnson and Ostendorf (1993), however, a more common understanding of impulsiveness (one probably shared by the clinicians cited by Trobst) is a rash, careless type of impulsivity, which 


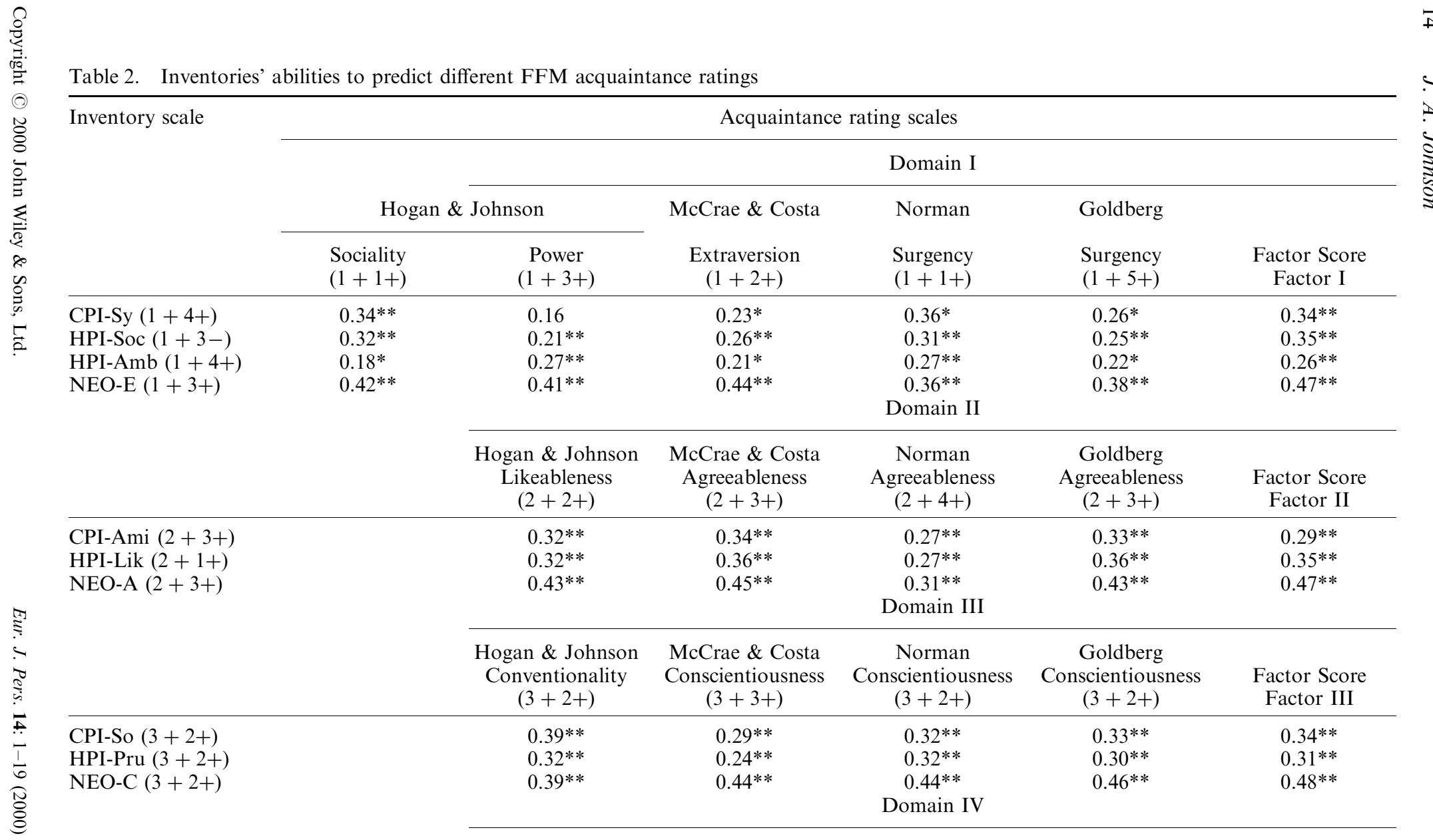


Table 3. Validity coefficients across different levels of AB5C correspondence between predictors and criteria

\begin{tabular}{lccccc}
\hline & \multicolumn{5}{c}{ Level of AB5C correspondence between predictors and criteria } \\
\cline { 2 - 6 } & $\begin{array}{c}\text { AB5C } \\
\text { identical }\end{array}$ & $\begin{array}{c}\text { Same } 1^{\circ} \\
\text { different } 2^{\circ}\end{array}$ & $\begin{array}{c}\text { Same } 1^{\circ} \\
\text { opposite } 2^{\circ}\end{array}$ & $Z$ & $p$ (one-tailed) \\
Predictor & 0.36 & 0.28 & 0.15 & 2.69 & $<0.005$ \\
All primary scales & 0.33 & 0.26 & 0.19 & 1.88 & $<0.03$ \\
NEO facets & 0.23 & 0.17 & 0.14 & 2.14 & $<0.02$ \\
HPI HICs & & & & & \\
\hline
\end{tabular}

falls into the 3-1+ AB5C facet. Once again, Hofstee et al. (1992, p. 154) were correct in suggesting that 'Inconsistencies among the levels [items, trait, and scale label], which are a source of misunderstanding and incorrect implications, may finally be traced [to inconsistent AB5C locations]'.

Duly noting that correlations between scales depend on their closeness in factor space, one can still ask why the NEO-PI-R scales unexpectedly out-predicted the CPI and HPI scales. One possible explanation is that the NEO-PI-R - in contrast to the $\mathrm{CPI}$ and HPI - was designed specifically to measure the Big Five domains; thus it would be no surprise that it predicts acquaintance ratings of the Big Five better than the CPI and HPI. This explanation is inadequate for two reasons.

First, the NEO-PI-R was not originally designed to assess the Big Five. The original NEO was conceived after a cluster analysis of Cattell's 16PF questionnaire revealed three clusters (Costa and McCrae, 1976). The original NEO, copyrighted in 1978, contained three primary scales; it was revised to include the Agreeableness and Conscientiousness domains only after consideration of the rating studies of John Digman (1979). In contrast, the original version of the HPI was designed specifically to cover the five rating factors in Norman's (1963) classic study (Johnson, 1997). The CPI may not have been designed around the Five Factor Model, but studies by Johnson (1987, 1997), Lanning and Gough (1991), and McCrae et al. (1993) indicate that the CPI is readily interpretable in terms of the FFM.

There is a second reason why the higher validity coefficients for the NEO-PI-R scales cannot be explained by saying that the acquaintance ratings of Big Five provide an easier target for this inventory. The authors of the CPI and HPI clearly state that predicting others' perceptions of the test-taker's personality is the raison d'être of their inventories. In fact, Hogan and Hogan (1992) assert that when their scales predict other criteria such as work performance, the mediating, causal factor is public reputation. If the CPI and HPI are supposed to predict observers' perceptions, using the Big Five rating dimensions as criteria would unfairly favor the NEO-PI-R only if we have left out other rating dimensions that might be better predicted by CPI or HPI scales. However, to date we have no replicable rating factors outside of the Big Five (Goldberg and Saucier, 1995).

A more plausible explanation for the superiority of the NEO-PI-R is purely psychometric. The heterogeneity of the HPI scales has become more pronounced from the original (Hogan, 1986) to revised (Hogan and Hogan, 1992) versions of the HPI. This is because the Hogans have begun to assign items to HICs and HICs to scales on common external correlations or on theoretical grounds rather than on internal psychometric considerations. The CPI scales, likewise constructed on 
empirical or rational grounds rather than internal consistency, are psychometrically heterogeneous. Whereas the HPI and CPI are well suited for predicting some complex, real-world phenomena, they are not the best predictors of factorially derived acquaintance ratings.

The NEO-PI-R domain-and-facet approach looks like one of the more promising approaches for mapping the subdomains of the five major personality domains. Nonetheless, interpretation of the NEO-PI-R may be enhanced by application of the AB5C model. The present study shows how the relative location of scales in AB5C space explains differences in predictive validity. This demonstration answers Johnson's (1994b) call to extend the AB5C model beyond its elegant internal mapping of trait words to multimethod demonstrations of pragmatic utility. In conclusion, as future researchers respond to Goldberg's (1999) request for comparative validity studies, they might be well advised to consider both the primary and secondary loadings of predictors and criteria.

\section{REFERENCES}

Cawley, M. J. III (1998). 'The virtues scale: a psychological examination of the structure of virtue and the relationships between virtue, personality, moral development, and epistemological style', doctoral dissertation, Pennsylvania State University, 1997; Dissertation Abstracts Internatonal B, 58: 3954.

Costa, P. T. Jr, Busch, C. M., Zonderman, A. B. and McCrae, R. R. (1986). 'Correlations of MMPI factor scales with measures of the five factor model of personalty', Journal of Personality Assessment, 50: 640-650.

Costa, P. T. Jr and McCrae, R. R. (1976). 'Age differences in personality structure: A cluster analytic approach', Journal of Gerontology, 31: 564-570.

Costa, P. T. Jr and McCrae, R. R. (1988). 'From catalog to classification: Murray's needs and the five-factor model', Journal of Personality and Social Psychology, 55: 258-265.

Costa, P. T. Jr and McCrae, R. R. (1992). Revised NEO Personality Inventory (NEO PI-R) and NEO Five-Factor Inventory (NEO-FFI): Professional Manual, Psychological Assessment Resources, Odessa, FL.

Digman, J. M. (1979). 'The five major domains of personality variables: Analysis of personality questionnaire data in the light of the five robust factors emerging from studies of rated characteristics', paper presented at the Annual meeting of the Society of Multivariate Experimental Psychology, Los Angeles, CA.

Digman, J. M. (1990). 'Personality structure: Emergence of the five-factor model', Annual Review of Psychology, 41: 417-440.

Digman, J. M. and Takemoto-Chock, N. K. (1981). 'Factors in the natural language of personality: Re-analysis, comparison and interpretation of six major studies', Multivariate Behavioral Research, 16: 149-170.

Goldberg, L. R. (1981). 'Language and individual differences: The search for universals in personality lexicons'. In: Wheeler, L. (Ed), Review of Personality and Social Psychology, Vol. 2, pp. 141-165, Sage, Beverly Hills, CA.

Goldberg, L. R. (1990). 'An alternative description of personality: The Big-Five factor structure', Journal of Personality and Social Psychology, 59: 1216-1229.

Goldberg, L. R. (1992). 'The development of markers for the Big-Five factor structure', Psychological Assessment, 1: 26-42.

Goldberg, L. R. (1993). 'The structure of phenotypic personality traits', American Psychologist, 48: 26-34.

Goldberg, L. R. (1999). 'A broad-bandwidth, public-domain personality inventory measuring the lower-level facets of several five factor models'. In: Mervielde, I., Deary, I., De Fruyt, F. 
and Ostendorf, F. (Eds), Personality Psychology in Europe, Vol. 7, Tilburg University Press, Tilburg, in press.

Goldberg, L. R. and Saucier, G. (1995). 'So what do you propose we use instead: A reply to Block', Psychological Bulletin, 117: 221-225.

Gough, H. G. (1987). California Psychological Inventory Administrator's Guide, Consulting Psychologists Press, Palo Alto, CA.

Hofstee, W. K. B. (1994). 'Who should own the definition of personality?', European Journal of Personality, 8: 149-162.

Hofstee, W. K. B., De Raad, B. and Goldberg, L. R. (1992). 'Integration of the big five and circumplex approaches to trait structure', Journal of Personality and Social Psychology, 63: $146-163$.

Hogan, R. (1983). 'A socioanalytic theory of personality'. In: Page, M.M. (Ed), 1982 Nebraska Symposium on Motivation: Personality-Current Theory and Research, pp. 58-89, University of Nebraska Press, Lincoln, NE.

Hogan, R. (1986). Hogan Personality Inventory Manual, National Computer Systems, Minneapolis, MN.

Hogan, R. (1996). 'A socioanalytic perspective on the five-factor model'. In: Wiggins, J.S. (Ed), The Five-Factor Model of Personality: Theoretical Perspectives, pp. 163-179, Guilford, New York.

Hogan, R. and Hogan, J. (1992). Hogan Personality Inventory Manual, Hogan Assessment Systems, Tulsa, OK.

Hogan, R. and Johnson, J. A. (1981). 'The structure of personality', paper presented at the 89th Annual Convention of the American Psychological Association, Los Angeles, CA, 1981.

John, O. P. (1990). 'The "Big-Five" factor taxonomy: Dimensions of personality in the natural language and in questionnaires'. In: Pervin, L.A. (Ed), Handbook of Personality Theory and Research, pp. 66-100, Guilford, New York.

Johnson, J. A. (1987). 'Influence of adolescent social crowds on the development of vocational identity', Journal of Vocational Behavior, 31: 182-199.

Johnson, J. A. (1994a). 'Clarification of factor five with the help of the AB5C model', European Journal of Personality, 8: 311-334.

Johnson, J. A. (1994b). 'Multimethod replication of the AB5C model of personality traits'. In: De Raad, B., Hofstee, W.K.B. and Van Heck, G.L. (Eds), Personality Psychology in Europe, Vol. 5, pp. 42-49, Tilburg University Press, Tilburg.

Johnson, J. A. (1997). 'Seven social performance scales for the California Psychological Inventory', Human Performance, 10: 1-30.

Johnson, J. A., Germer, C. K., Efran, J. S. and Overton, W. F. (1988). 'Personality as the basis for theoretical predilections', Journal of Personality and Social Psychology, 55: 824-835.

Johnson, J. A. and Ostendorf, F. (1993). 'Clarification of the five factor model with the abridged big five dimensional circumplex', Journal of Personality and Social Psychology, 65: $563-576$.

Lanning, K. and Gough, H. G. (1991). 'Shared variance in the California Psychological Inventory and the California Q-Set', Journal of Personality and Social Psychology, 60: 596-606.

McCrae, R. R. and Costa, P. T. Jr (1985a). 'Comparison of EPI and psychoticism scales with measures of the five-factor model of personality', Personality and Individual Differences, $\mathbf{6}$ : 587-597.

McCrae, R. R. and Costa, P. T. Jr (1985b). 'Updating Norman's "adequate taxonomy": Intelligence and personality dimensions in natural language and in questionnaires', Journal of Personality and Social Psychology, 49: 710-721.

McCrae, R. R. and Costa, P. T. Jr (1987). 'Validation of the five-factor model across instruments and observers', Journal of Personality and Social Psychology, 52: 81-90.

McCrae, R. R. and Costa, P. T. Jr (1989a). 'Reinterpreting the Myers-Briggs Type indicator from the perspective of the five-factor model of personality', Journal of Personality, 57: $17-40$.

McCrae, R. R. and Costa, P. T. Jr (1989b). 'The structure of interpersonal traits: Wiggins's circumplex and the five-factor model', Journal of Personality and Social Psychology, 56: $586-595$. 
McCrae, R. R., Costa, P. T. Jr and Piedmont, R. L. (1993). 'Folk concepts, natural language, and psychological constructs: The California Psychological Inventory and the five-factor model', Journal of Personality, 61: 1-26.

McNemar, Q. (1969). Psychological Statistics, 4th edn, Wiley, New York.

Meng, X.-L, Rosenthal, R. and Rubin, D. B. (1992). 'Comparing correlated correlation coefficients', Psychological Bulletin, 111: 172-175.

Norman, W. T. (1963). 'Toward an adequate taxonomy of personality attributes: Replicated factor structure in peer nomination personality ratings', Journal of Abnormal and Social Psychology, 66: 574-583.

Tellegen, A. and Waller, N. G. (1999). 'Exploring personality through test construction: Development of the Multidimensional Personality Questionnaire'. In: Briggs, S.R., Cheek, J.M. and Donahue, E.M. (Eds), Handbook of Adult Personality Inventories, Plenum, New York, in press.

Thurstone, L. L. (1934). 'The vectors of mind', Psychological Review, 41: 1-32.

Trobst, K. K. (1999). 'Assessing personality change after traumatic brain injury', colloquium talk delivered to the Department of Psychology, Pennsylvania State University, 1999.

Wiggins, J. S. and Broughton, R. (1991). 'A geometric taxonomy of personality scales', European Journal of Personality, 5: 343-365. 